\title{
SIDEROSIS OF THE GLOBUS PALLIDUS IN A MONKEY
}

BY

\section{P. GLEES}

(From the Department of Human Anatomy, Oxford)

(Received 23Rd SePtember, 1943)

THE following case is reported as a contribution to the records of comparative pathology. In the course of examining a brain of an apparently normal mangabey monkey. (Cercocebus torquatus atys), deposits were observed in the globus pallidus of both sides accompanied by rarefactions of the surrounding nervous tissue.

The monkey, O.M.487, a four year old male with a body-weight of 5,200 gms., had been maintained on a normal diet for three years in this department. For 41 days before the animal was killed it received a daily injection of $100 \mathrm{y}$. of œstrone monobenzoate with a view to studying the influence of this substance on the reproductive tract. At autopsy none of the organs showed any abnormality, with the exception of some epithelial hyperplasia in the accessory sexual organs. The brain was prepared for a study of the normal histology of the basal ganglia of a monkey.

\section{Macroscopical and microscopical examination of the brain}

Macroscopically the membranes, vessels, and gross structure of the brain appeared to be normal. However, when slicing the brain, a gritty substance was detected in the region of the globus pallidus. Sections stained with toluidin blue or hæmatoxylin showed the following picture: The external and internal divisions of the globus pallidus of both sides are crowded with patches of deposits staining a deep blue. The individual deposits are very irregular in shape, reaching up to a diameter of $3 \mathrm{~mm}$. No marked glial reaction around them is visible, nor is there any leucocytic infiltration. Occasionally the deposits are intimately related to blood vessels, embedded in the wall between the tunica media and tunica adventitia. In most cases, however, they are distributed in the ground substance of the nervous tissue. In their general distribution the deposits are confined to the anterior two-thirds of the globus pallidus, and they are not present in any other part of the brain. The nervous tissue of the globus pallidus shows distinct pathological changes. The nerve cells surrounding the deposits have undergone various amounts of destruction. Silversections show that the plexus of nerve fibres is less dense than in the normal globus pallidus, and many of the fibres show degenerative changes such as fragmentation and irregular thickenings. The deposits were first thought to be entirely of a calcareous nature, but they were found to give a strong positive reaction for iron in preparations treated with hydrochloric acid and potassium ferrocyanide. In these preparations the substance of the globus pallidus itself also stains a more intense blue than normal.

\section{Discussion}

The presence of iron in the globus pallidus, varying considerably in amount in different mammalian species, has been well established by histochemical reactions (Spatz, 1922), and under pathological conditions the content of iron may be greatly increased (Hurst, 1926). Bielschowsky (1919) stated that the presence of deposits (which he assumed to be of calcareous nature) is fairly frequent in the globus pallidus of elderly people. Hurst (1926) showed in a careful analysis of a hundred brains with various pathological conditions

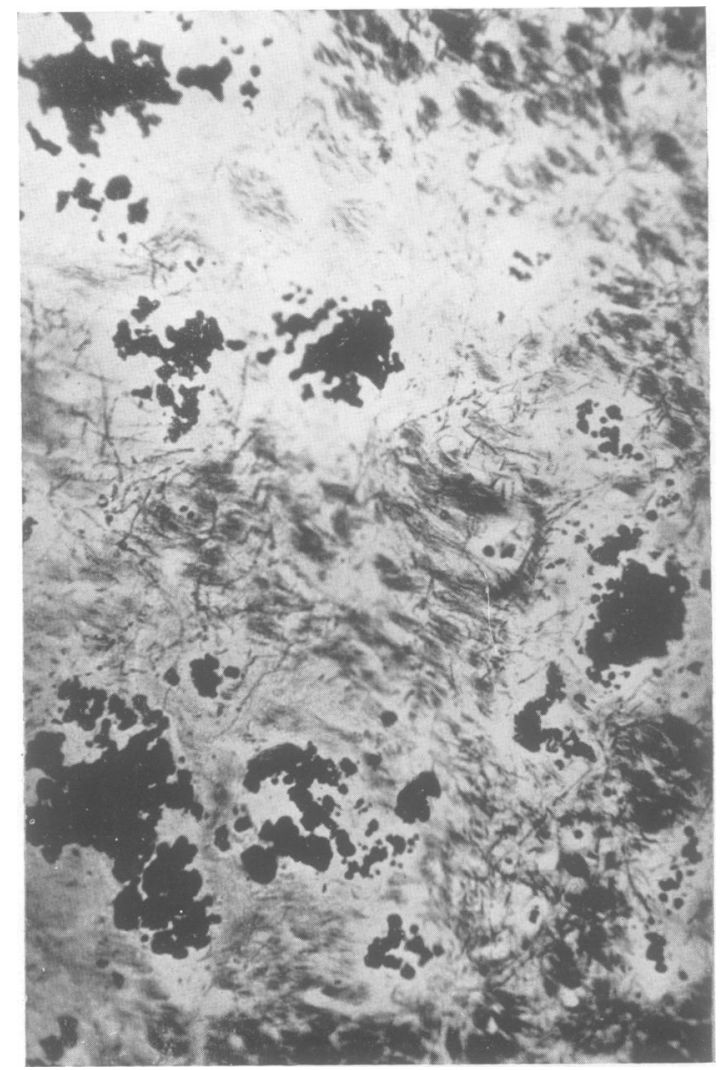

Microphotograph of the globus pallidus stained with silver nitrate showing the deposits of iron and the surrounding areas of rarefaction of the nervous substance $\times 80$. 
that in 50 per cent. of cases the so-called calcifications of the vessels in the globus pallidus consisted mostly of iron. Bielschowsky described the deposit as occurring round larger vessels and also in the wall of capillaries. This vascular relation is also emphasized by Hurst (1934), who pointed out that the condition is at least as frequent as a senile change in horses as in man. In a survey of the pathology of the monkey, Fairbrother and Hurst (1932) mention the occasional occurrence of calcification combined with siderosis in the vessels of the basal ganglia.

In the present case no evidence was found of any inflammatory condition which might have been associated with the siderosis. In contrast with Hurst's observations, also, the main precipitations had no definite relation to blood vessels. On the contrary, the sections indicate that the deposits did not occur primarily in the vessel walls but in the nervous substance of the globus pallidus. This suggests that the condition may have arisen as the result of some metabolic dysfunction of the globus pallidus itself, leading to an increase above the normal level of the iron content of this structure with a consequent precipitation, and that the deposits found in the walls of the vessels had been transported there from the surrounding tissue.

The question naturally arises whether the siderosis in this monkey might have any relation to its treatment during life with injections of œstrone monobenzoate. This possibility deserves consideration since the frequent association of siderosis of the globus pallidus with senility suggests that it may ultimately be due to the effects of hormonal disturbances on metabolism. The extensive studies of Meyer (1936) have already shown that the globus pallidus is particularly vulnerable to derangements of metabolism produced by various poisons. In the present case the period of injection seemed to have been too short to account for the massive changes which were found, but it is hoped to collect further material to inquire into the possibility of a hormonal basis for the condition observed.

In spite of the extensive damage to the globus pallidus no abnormalities in behaviour in the monkey were noted. This is somewhat remarkable, for an equivalent amount of damage involving the globus pallidus in man would undoubtedly have led to a marked clinical picture. However, it is interesting to note that in three monkeys with large bilateral lesions of the globus pallidus Ranson and Berry (1941) observed no signs comparable with those of pallidal disease in man. Cogwheel resistance to passive movements and Parkinsonian tremor were absent, and choreiform and athetoid movements did not occur. Wilson (1914) made unilateral lesions of the globus pallidus of monkeys and kept them under observation for several weeks. He found that small lesions caused no symptoms and even when the destruction was extensive no tremor or involuntary movements were observed.

\section{Summary}

A case of marked siderosis in the globus pallidus of both sides is described in a monkey. In spite of severe bilateral pathological changes affecting the globus pallidus no disturbance of normal behaviour was observed in the monkey during life.

\section{REFERENCES}

Bielschowsky, M. (1919-20). J. Psychol. Neurol, $25,1$. Fairbrother, R. W., and Hurst, E. W. (1932). J. Path. Bact., 35, 867.

Hurst, E. W. (1926). Ibid., 29, 65.

- (1934). Amer. J. Path., 10, 795.

Meyer, A. (1936). Proc. roy. Soc. Med., 29, 1175.

Ranson, S. W., and Berry, C. (1941). Arch. Neurol. Psychiat., Chicago, 46, 504.

Spatz, H. (1922). Z. ges. Neurol. Psychiat., 77, 261.

Wilson, S. A. K. (1914). Brain, 36, 427. 